\title{
A complexa delimitação territorial nas Minas Gerais do século XIX: um exercício de representação cartográfica do primitivo distrito de Juiz de Fora
}

The complexity of territorial delimitations in the Minas Gerais of the 19th century: an exercise of cartographic representation of the primitive district of Juiz de Fora

\section{Pedro José de Oliveira Machado'}

\section{RESUMO}

Nesse artigo são apresentados os resultados da pesquisa intitulada 'Evolução territorial do município de Juiz de Fora', sendo destacada sua primeira constituição

territorial, no período anterior à emancipação político-administrativa. Os objetivos foram comprovar, oficial e legalmente, a condição de Juiz de Fora como Distrito de Barbacena e apresentar cartograficamente seus limites territoriais. $\mathrm{O}$ trabalho fundamenta-se em uma base jurídica, especialmente pelo disposto nas leis provinciais $n^{\circ} 147$, de 6 de abril de 1839 e $n^{\circ}$ 291, de 26 de março de 1846, e em uma base cartográfica, apoiada nas Cartas Planialtimétricas do IBGE, na escala 1:50.000, nas Cartas Juiz de Fora e Palmira, produzidas pela Commissão Geográphica e Geológica de Minas Gerais, de 1924, na escala 1:100.000 e no mapa de Theodoro, de 1847. Os principais resultados são a comprovação legal da condição de Juiz de Fora como Distrito de Barbacena na primeira metade do século XIX e a produção de um mapa que apresenta a abrangência territorial aproximada dessa conformação administrativa.

Palavras-chave: Delimitação municipal; Geografia Histórica; Território

\section{ABSTRACT}

This article presents the results of the research entitled 'Territorial evolution of the county of Juiz de Fora', highlighting its first territorial constitution, in the period

before political-administrative emancipation. The objectives were to officially and legally prove the status of Juiz de Fora as District of Barbacena and present cartographically its territorial limits. The work was thus based on a legal basis, in particular by the provisions of Provincial Laws 147, of April 6, 1839 and 291, of March 26, 1846, and on a cartographic basis, supported by the IBGE Maps, on the scale 1: 50,000, in the Letters Juiz de Fora and Palmira, produced by the Commission Geographica and Geologica of Minas Gerais, 1924, scale 1: 100,000 and in the Theodoro map, 1847. The main results are the legal proof of the status of Juiz de Fora, as District of Barbacena, in the first half of the nineteenth century and the production of a map that shows the approximate territorial coverage of this administrative conformation.

Keywords: Historical Geography; Municipal delimitation; Territory 


\section{INTRODUÇÃO}

As pesquisas que temos realizado sobre o processo de formação territorial de Juiz de Fora - maior município da Zona da Mata Mineira, e que abriga uma população de 564.310 habitantes, segundo estimativas do Instituto Brasileiro de Geografia e Estatística para 2018 - tem apontado, dentre outros aspectos, para uma grande dificuldade de representar cartograficamente os municípios mineiros do período imperial, especialmente em meados do século XIX, quando ocorre a criação de muitos deles, como é o caso de Juiz de Fora.

As dificuldades decorrem de várias causas, entre as quais a ausência de bases cartográficas específicas da época; a presença de uma legislação pouco detalhada e/ou que deixa dúvidas quanto à correta interpretação das limitações territoriais; e, sobretudo, em razão da composição dos novos municípios ter se baseado, quase sempre, nas paróquias, unidades eclesiásticas existentes "desde os primeiros anos do povoamento" (COSTA, 1997, p.26), mas que apresentavam uma característica peculiar, pois embora até possuíssem território delimitado, não possuíam autonomia.

Um dos grandes problemas para a delimitação dos municípios desse período decorre exatamente da adoção dessas paróquias (ou freguesias), pois elas tinham sua abrangência dada, quase sempre, por fazendas, ou seja, por extensas propriedades rurais dotadas de limitação pouco objetiva e que muito se alteraram desde então (por desmembramentos, doações, partilhas etc.). Se a representação cartográfica desses municípios - que eram instâncias político-administrativas autônomas - constitui um problema, pior ocorre com unidades menores, que não gozavam de autonomia, como o caso dos distritos. Por essas razões mapear os territórios municipais do século XIX tem se mostrado um exercício tão difícil quanto estimulante.

Não obstante, deve-se destacar que nos últimos tempos os estudos acerca da Geografia Histórica da Zona da Mata Mineira têm experimentado um desejável crescimento no número de trabalhos e pesquisas, muitos dos quais tendo como foco a produção, constituição e ordenamento territorial, valendo citar, dentre outros, 
Giovanini (2006), Castro (2008), Carrara (2009), Andrade (2010), Saraiva; Silva (2010), Vanni (2013), Barbosa (2017), Castro (2017), Ferreira (2017), Machado; Santos (2017), Moura; Machado; Zaidan (2017), Machado (2018a) e Machado (2018b).

Nesses estudos um dos pontos convergentes entre História e Geografia tem sido a Cartografia. Como citado por Castro (2017, p.15) ela tem sido fundamental para a interação dessas duas disciplinas, pois representa "a linguagem por excelência dos geógrafos e uma fonte riquíssima de informações para os historiadores". Nesse aspecto merece destaque especial a metodologia desenvolvida por esse mesmo autor, que teve como meta criar um banco de dados digitais a partir de georreferenciamento e vetorização, no software ARC GIS, de mapas históricos da Capitania de Minas Gerais dos séculos XVIII e XIX (CASTRO, 2017, p.28).

Também na seara da Geografia Histórica, que segundo Erthal (2003, p.30) tem o papel, dentre outros, "de se preocupar em recuperar as espacialidades pretéritas que marcam as espacialidades atuais", o presente trabalho tem o objetivo de apresentar e comprovar a condição administrativa de Juiz de Fora no período anterior à sua emancipação, ainda como Distrito de Barbacena, e a partir daí mapear seu território original.

As fontes de informação utilizadas na pesquisa podem ser divididas em 3 frentes, representadas por uma base bibliográfica, uma base jurídica e uma base cartográfica. 1) A base bibliográfica abrangeu o levantamento de obras de muitos pesquisadores da historiografia regional, e inclusive alguns documentos por eles citados, constituindo-se, portanto, de fontes secundárias; 2) A base jurídica, por sua vez, concentrou-se em duas linhas: a) Como a Lei Geral de $1^{\circ}$ de outubro de 1828 estabeleceu, em seu Artigo 55, que “às câmaras compete repartir o termo em districtos, nomear os seus officiaes e dar-lhes títulos [...]", tornou-se necessária uma pesquisa junto ao arquivo histórico da Câmara de Barbacena, município ao qual pertencia Juiz de Fora. Contudo, e infelizmente, nos foi informado (oficialmente, em 19 de março de 2018) que para o período de interesse - a primeira metade do século XIX - "a documentação da Câmara de Barbacena não existe"; b) a outra parte do 
levantamento jurídico se baseou no estudo de todas as leis provinciais mineiras, de 1835 até 1850, quando o município é criado. Essa pesquisa foi realizada, sobretudo, no site eletrônico do Arquivo Público Mineiro (APM), que disponibiliza toda legislação de Minas Gerais até o início da República; 3) para a elaboração do mapa representativo do distrito de Juiz de Fora foram utilizadas como bases as Cartas planialtimétricas do IBGE, na escala 1:50.000 (Folhas Matias Barbosa, Juiz de Fora, Ewbank da Câmara, Mar de Espanha, São João Nepomuceno e Santa Bárbara do Monte Verde). Nelas foram plotados os limites territoriais, ponto por ponto, de acordo com o disposto na legislação específica da época.

\section{O DISTRITO DE JUIZ DE FORA}

Antes de 1850 - ano em que se dá a criação da Vila de Santo Antônio do Paraibuna e da Paróquia de Santo Antônio do Juiz de Fora, através da Lei Provincial ${ }^{\circ}$ 472, de 31 de maio - a condição político-administrativa e, sobretudo, a conformação territorial de Juiz de Fora constituem tarefas de difícil determinação. Inúmeras fontes de consulta, não raro, ignoram esse período inicial de formação do município, seja por não se constituir objeto específico de estudo da rica historiografia local, seja pelo fato de se tratar de um objetivo mais afeito à Geografia, por seu caráter de buscar entender a construção do território. De qualquer forma, trata-se de um período histórico longo e que abrange uma discussão importante, que é a constituição da base territorial inicial do futuro município.

Nesse período, anterior à sua emancipação, Juiz de Fora está subordinada, segundo a organização eclesiástica, à Paróquia de Nossa Senhora da Glória de Simão Pereira e, de acordo com a organização administrativa, faz parte do imenso Termo (município) de Barbacena, situação que somente irá se alterar com sua emancipação, em 1850 e, sendo assim, não gozava de autonomia político-administrativa, o que apenas ocorria com vilas e cidades. 
Contudo, esse período se torna importante por ter abrigado suas primeiras demarcações territoriais legais. E é exatamente nesse aspecto que surge um tema pouco explorado, muito relevante, mas ainda nebuloso na história da consolidação territorial local. A partir do final da década de 1820, alguns estudos e documentos, inclusive legais e jurídicos, começam a tratar Juiz de Fora como um Distrito de Barbacena e não como um simples arraial. Isso é de grande relevância, pois o fato de tratar-se de um distrito, embora não contasse com gestão administrativa própria, implicava, dentre outras questões, em ter um território delimitado. Como salientam Saraiva e Silva (2010, p.3) “quando uma 'localidade' ou 'povoado' era elevado à categoria de 'distrito' passava a contar com a presença de, ao menos um subdelegado, além de qualificar aquela comunidade a solicitar favores e verbas por parte da província". Enquanto o arraial pudesse ter duração efêmera (GUIMARÃES, 2006, p.41), o distrito era uma forma de reconhecimento da consolidação e do desenvolvimento de uma povoação, uma instância hierárquica urbana diferenciada, sendo mesmo, comumente, uma condição pretérita e necessária para sua elevação à categoria de vila.

No entanto, até o final da década de 1830, Juiz de Fora não constituía suficiente consolidação econômica ou demográfica capaz de fazer com que fosse elevada ou reconhecida como um distrito (MACHADO, 2018b). Embora existam registros do topônimo 'Juiz de Fora' no início do século XVIII (SANTIAGO, 1979, p.20; 1985, p.23; LESSA, 1985, p.26), tratava-se de um tosco e acanhado povoado, que somente iria conhecer maior desenvolvimento com a consolidação da cultura cafeeira e, em paralelo, com a Estrada do Paraibuna, aberta por Halfeld, a partir de 1836, verdadeiramente responsável por originar seu processo de urbanização, a partir da implantação de sua principal via estruturadora - a atual Avenida Barão do Rio Branco - e por trasladar a povoação para a margem direita do Rio Paraibuna, "trocando a geomorfologia dos morros pela da planície" (MACHADO; SANTOS, 2017, p.74).

Bastos (2004, p.75) destaca que durante o século XVIII, o primitivo povoado de Juiz de Fora ou Santo Antônio da Boiada, "não foi o ponto de maior movimento ao 
longo do Caminho Novo. Bem mais movimentados foram Simão Pereira, depois Matias Barbosa e Chapéu d'Uvas". Segundo Valverde (1958, p.27) por volta de 1820, "Juiz de Fora era então um centro tão diminuto que apenas é citado de passagem, mais para explicar seu curioso nome que por outro motivo". Outros importantes pesquisadores reforçam essas ideias. De acordo com Oliveira (1958, p.55; 1966, p.1112), por exemplo, "de povoado só se falou, depois de 1835, no de Santo Antônio do Paraibuna, que não se iniciou em nenhum daqueles pousos, perto do Rio Paraibuna, mas bem distante dele, na margem oposta [...]". Segundo Barbosa (1971, p.254), "até 1836, não havia povoado algum na margem direita do Paraibuna, onde depois surgiu o arraial". Andrade (2010, p.85) explica que "a primeira povoação existente nas cercanias, única até 1836 , foi o arraial de Santo Antônio do Paraibuna, localizado à margem do Caminho Novo, no sopé do Morro da Boiada".

Muitas obras de relevância, quando tratam do seu histórico políticoadministrativo, não fazem nenhuma menção a esse status hierárquico que teria tido Juiz de Fora. A obra Ephemérides Mineiras (VEIGA, 1897, p.316) não traz nenhuma informação sobre Juiz de Fora como distrito de Barbacena. A Enciclopédia dos Municípios Brasileiros (IBGE, 1959, p.388), quando apresenta sua "formação administrativa" nada menciona a respeito da figura do distrito. Pelo contrário, trata a localidade, antes de 1850, como povoação ou arraial (IBGE, 1959, p.384). Também no Dicionário Histórico Geográfico de Minas Gerais (BARBOSA, 1971, p.254), não há referência ao tema. O livro Toponímia de Minas Gerais (COSTA, 1997, p.257), uma das principais e mais completas fontes de referência para o estudo da formação administrativa dos municípios do Estado, não faz nenhuma alusão ao assunto quando trata do histórico político-administrativo local. Mesmo a recente obra do Tribunal de Justiça do Estado de Minas Gerais, intitulada Comarcas de Minas (MINAS GERAIS, 2016, p.43), quando aborda o histórico do município (no período denominado "anterior à criação do município-vila"), também não apresenta nenhuma informação sobre sua condição de distrito. No sítio eletrônico da biblioteca do IBGE não há referência à condição de Juiz de Fora como distrito de Barbacena. No sítio eletrônico 
da Assembleia Legislativa do Estado de Minas Gerais (ALMG), o que existe sobre Juiz de Fora é um quadro geral, do qual constam informações básicas, com exceção ao item "criação do distrito", que aparece assinalado como "sem registro". O mesmo acontece na obra "As denominações urbanas de Minas Gerais", do Instituto de Geociências Aplicadas (IGA, 1993, p.50).

Outros autores, por sua vez, admitem a possibilidade de Juiz de Fora ter alcançado o status de distrito, contudo, sem apresentar, na maioria das vezes, documento probatório ou fonte legal. Pinto (1906, p.649) conclui que "mais ou menos de 1838 deve datar a criação do districto de Juiz de Fora ou da Boiada", embora faça posterior ressalva, em nota de rodapé, na mesma página, de que "não encontramos a lei que cria o districto". Santiago (1979, p.31) afirma que "elevado o pequeno povoado à categoria de distrito, suas divisas com os de Simão Pereira e São Francisco de Paula foram estabelecidas pelas leis 147, de 6 de abril de 1839 e 291, de 26 de março de 1846", havendo aqui uma importante e rara referência legal à citada condição administrativa. O portal eletrônico da Prefeitura Municipal de Barbacena também afirma que "Juiz de Fora foi distrito de Barbacena até 1850", sem também oferecer referências à afirmação.

Por outro lado, muitas obras, trabalhos e documentos, igualmente relevantes, como os apresentados e discutidos a seguir, levam a crer, direta ou indiretamente, que o distrito tenha existido, mesmo que possa não ter sido objeto de criação oficial ou legal específica,

No endereço eletrônico da Câmara Municipal de Juiz de Fora existe a informação de que a instalação da câmara, em 7 de abril de 1853, "foi o verdadeiro ato de emancipação do distrito de Santo Antônio de Juiz de Fora da Comarca do Paraibuna, criado em 28 de abril de 1828, e elevado a Vila, em 31 de maio de 1850". Embora seja citada com precisão a data de criação do distrito não há nenhuma referência ao ato legal de sua origem (lei, decreto etc.). Além disso, observa-se também que a redação leva ao entendimento de que o distrito pertenceria, nessa data, à Comarca do 
Paraibuna, que, contudo, só fora criada 5 anos mais tarde, pela Resolução de 30 de junho de 1833.

De acordo com Fazolatto (2004, p.10; 2007, p.19), a influência de Antônio Dias Tostes, tios e primos, "nomes de destaque na política regional, foram fundamentais para a criação, em $1^{\circ}$ de outubro de 1828, do Distrito de Santo Antônio do Juiz de Fora, do município de Barbacena [...]". Por certo essa afirmação deve se constituir como resultado de profunda pesquisa, cabendo, no entanto, uma questão relevante. A referida Lei Geral de $1^{\circ}$ de outubro de 1828 regulamentava o funcionamento das câmaras de vereadores, das vilas e cidades de então, bem como disciplinava as eleições que nelas se dariam a cada quatro anos, não estando, a citada criação, explícita no corpo dessa lei. Por outro lado, em 19 de maio de 1830, o Jornal 0 Universal, de Ouro Preto ( $N^{\circ} 442$, p.2), publicou uma Resolução do Conselho Geral da Província de Minas Gerais, em resposta a duas representações da Câmara da Vila de Barbacena (datadas de 30 de julho e 17 de dezembro de 1829), acerca da criação de escolas para meninos e para meninas, em algumas localidades do município dessa Vila. Importante observar que no Artigo $2^{\circ}$ da Resolução, o Conselho questiona (e adia) a criação de uma dessas escolas, para o local denominado "Districto de Santo Antônio do Juiz de Fora".

Godoy et al. (2003, p.2) assinalam que o Censo de 1831/1832, organizado sob a forma de listas nominativas de habitantes, "é o mais extenso e circunstanciado levantamento populacional do período provincial mineiro, além de ser o maior conjunto de informações nominais de natureza censitária remanescente para o período imperial brasileiro". Esse censo, ou Lista Nominativa, que compõe o acervo do APM é, para Juiz de Fora, datado de 18 de novembro de 1831, e também apresenta seus dados em relação ao denominado "Distrito de Santo Antônio de Juiz de Fora", ligado à Freguesia de Simão Pereira, ao Termo de Barbacena e à Comarca do Rio das Mortes (APM, Caixa sete, Documento quatro). Mais uma vez - agora em um documento oficial - Juiz de Fora aparece na condição de distrito de Barbacena. 
No entanto, cumpre destacar, em paralelo, o conteúdo de outra obra, que apresenta informação bastante diversa. Cunha Matos (1981, p.127), em seu livro Corografia Histórica da Província de Minas Gerais (Volume I), apresenta a descrição das comarcas e termos que compunham a Província de Minas Gerais, no ano de 1837, embora os dados que apresenta devam corresponder ao ano de 1831. A própria divisão territorial mostrada para a Província, em cinco comarcas, não reflete a situação que existia em 1837. A Resolução de 30 de junho de 1833 havia estabelecido a divisão da Província em nove comarcas. Assim, por exemplo, a Comarca do Rio Paraibuna, criada pela citada Resolução, formada pelos termos das vilas de Barbacena, Baependy e Pomba, não aparece no trabalho de Matos (1981). Seja como for, 1831 (o mais provável) ou 1837, o Termo da Vila de Barbacena encontrava-se dividido em quatro distritos (Vila de Barbacena, Engenho do Mato, Simão Pereira e Ibitipoca) e para cada um deles são listados os principais arraiais e localidades vinculados (MATOS, 1981, p.127-133). Pelo conteúdo desse trabalho, Juiz de Fora não é relacionado como um dos distritos de Barbacena e nem mesmo aparece na listagem das localidades a eles ligadas.

Outro acontecimento importante, na busca de elucidar essa situação administrativa local, remete-se a 1833. Nesse ano, ao que indicam algumas publicações (OLIVEIRA, 1966, p.18; SANTIAGO, 1979, p.31), José Antônio da Silva Pinto, o Barão da Bertioga, importante cafeicultor da região, atuava como representante na Câmara Municipal de Barbacena. Oliveira (1966, p.18) informa que não encontrou, em Barbacena, o livro de atas desse período, para confirmar tal situação, mas que não a colocava em dúvida, especialmente por se tratar de Silva Pinto. O fato de se fazer representar na Câmara de Vereadores de Barbacena implica concluir, em princípio, que Juiz de Fora devesse se constituir num distrito, para gozar de tal situação. Contudo, o próprio Oliveira (1966, p.18) explica “[...] que Bertioga não representava a localidade, porque esta, ainda não existia, mas o distrito, em cujo território ela surgiu em seguida". Como se vê, a citação não esclarece a que distrito se refere. Pode-se 
supor que, provavelmente, devesse se tratar de Simão Pereira, que segundo Matos (1981, p.130), já ocupava essa posição.

O ano de 1839 é bastante auspicioso à pesquisa pela primeira constituição administrativa local. Nesse ano, a Lei Provincial $n^{\circ}$ 147, de 6 de abril, não só trata oficialmente do distrito, como estabelece suas primeiras demarcações territoriais, como pode ser observado pelo conteúdo de seu Artigo $3^{\circ}$ :

Os limites entre os distritos de Simão Pereira, e o do Juiz de Fora, ou da Boiada, no Município de Barbacena, serão além dos das antigas aplicações, as serras e montes mais elevados, desde a Fazenda de Mathias Barbosa até o rio, e distrito do Kágado.

Ainda por essa lei, no seu Artigo $4^{\circ}$ lê-se:

As câmaras municipais, a cujos termos pertencem os distritos novamente criados, farão proceder à eleição dos juízes de paz para os referidos distritos, e os eleitos servirão até a época das eleições gerais.

Parece, de fato, ter havido tal eleição (ou indicação), pois dois anos depois ocorria, como descrevem Pinto (1906) e Lessa (1985), a primeira audiência de um Juiz de Paz, presidida por José Caetano Rodrigues Horta, em sua residência. Segundo Pinto (1906, p.649) o fato teria ocorrido em 18 de setembro de 1841 e de acordo com Lessa (1985, p.47), em 18 de outubro do mesmo ano. “Nos autos, consta ser ele o Juiz de Paz do Curato de Santo Antônio do Juiz de Fora, Termo de Barbacena, Comarca do Paraibuna" (LESSA, 1985, p.47).

O conteúdo desses artigos da Lei Provincial n 147/1839 permite que se tenham, pelo menos, duas possibilidades de interpretação: 1) de maneira mais imediata, se a lei estava estabelecendo os limites entre dois distritos é natural admitir que eles já existissem; 2) outra interpretação, bem diferente, e que se afigura como mais correta e coerente, relaciona-se ao entendimento mais detalhado da expressão utilizada no corpo do Artigo $4^{\circ}$ da mencionada lei. Lá se encontra a expressão “[...] os distritos novamente criados [...]". Nesse caso e, nessa época, a palavra 'novamente' não 
guardava o sentido comum, que tem hoje, de repetição, de 'outra vez', mas de 'modo' ou 'maneira' (como o são felizmente, de maneira feliz, ou extremamente, de maneira extrema, por exemplo). Assim, os distritos não estariam sendo criados 'outra vez', mas de 'maneira nova'. Nesse entendimento, a criação do Distrito de Juiz de Fora teria ocorrido - como nos parece - exatamente com a edição dessa lei.

A Lei Provincial $n^{\circ}$ 291, de 26 de março de 1846 consolida a condição administrativa do distrito. Por essa lei são estabelecidas as divisas do Distrito do Juiz de Fora com os distritos de São Francisco de Paula e Simão Pereira, bem como os limites entre esses dois últimos, como pode ser observado pelo disposto nos seus $\operatorname{artigos} 4^{\circ}, 5^{\circ}$ e $6^{\circ}$, transcritos a seguir.

Art. $4^{\circ}$ - As divisas do Distrito de Simão Pereira pelo lado limítrofe com o de São José, e São Francisco de Paula, ficam sendo do Pião da Fazenda de Mathias Barboza, existente no território do antigo Registro ao Córrego do Macuco, pelo Serrote da Pipa em direitura à Ponte de São Mateus no Rio do Peixe, e desta Ponte pelo braço da Serra Negra até ao lugar denominado Torreão, e deste pela continuação de um braço da mesma Serra, águas vertentes para o Rio Paraibuna, até findar no Rio Preto, na Fazenda da União, que também ficará pertencendo ao mencionado Distrito de Simão Pereira.

Art. $5^{\circ}$ - As divisas do Distrito do Juiz de Fora com o de São Francisco de Paula, e Simão Pereira, serão pela Serra dos Pintos, águas vertentes para o Rio Paraibuna, até o Serrote da Pipa, e daí a findar no Pião da Fazenda de Mathias Barboza.

Art. $6^{\circ}$ - Estes Distritos assim alterados formarão a Freguesia de Simão Pereira, cujas divisas continuarão a ser as mesmas existentes até agora, salvas as alterações feitas na presente Lei.

Uma observação importante e que consolida a interpretação de que o Distrito de Juiz de Fora tenha sido criado, de fato, pela Lei Provincial $n^{\circ} 147$, de 1839, diz respeito ao teor do Artigo $6^{\circ}$ da Lei 291/1846, quando menciona que "estes distritos assim alterados [...]", diferente da expressão "novamente criados", utilizada na lei de 1839. Da mesma forma, o trecho do artigo que diz "[...] cujas divisas continuarão a ser as mesmas existentes até agora [...]" deixa claro que elas já existiam. Também é possível 
concluir, ainda pelo conteúdo do Artigo $6^{\circ}$, que a Freguesia de Simão Pereira passava a ser constituída pelos quatro distritos: Simão Pereira, São José (que corresponde atualmente a São José das Três Ilhas, distrito do município de Belmiro Braga), São Francisco de Paula (que corresponde à localidade de Torreões, distrito do atual município de Juiz de Fora) e Juiz de Fora, todos pertencentes ao Termo de Barbacena.

Cumpre, entretanto, fazer uma importante observação que, mais uma vez, ajuda a não esclarecer, em definitivo, a situação administrativa de Juiz de Fora, no período anterior à sua emancipação. No livro de Esteves e Lage (1915), importante obra sobre a história da cidade, constam várias escrituras, tendo por referência o livro de Escrituras e Procurações da Câmara. São, em sua maior parte, transações imobiliárias, de compra e venda de terras. Contudo, estes documentos cartoriais tratam Juiz de Fora como distrito de Barbacena, de 1837 (data, portanto, anterior à lei de 1839) até 1846. No início das escrituras constava o seguinte cabeçalho geral, como apresentado no exemplo a seguir:

Saibam quantos este público instrumento virem de Escriptura [...], que no ano de nascimento de Nosso Senhor Jesus Cristo, de mil oitocentos e quarenta e seis, do vigésimo quinto da Independência do Império do Brasil, aos quatorze dias do mês de maio deste mesmo ano, neste Distrito de Santo Antônio do Juiz de Fora, Freguesia de Simão Pereira, Termo de Barbacena, Comarca do Rio Parahybuna, Província de Minas Gerais, em meu cartório [...] (ESTEVES e LAGE, 1915, p.53).

Outras situações confusas e conflitantes, até mesmo legais, ocorrem depois da promulgação da lei de 1846. Em 1847, por exemplo, a Lei Provincial nº 320, de 22 de março daquele ano, estabeleceu, em seu Artigo $1^{\circ}$ que "ficam criadas as seguintes Aulas de Instrução Primária do $1^{\circ}$ grau" e, a partir daí enumera uma série de locais, inclusive, no parágrafo $6^{\circ}$, quando menciona o "Arraial do Juiz de Fora, Termo de Barbacena". Por outro lado, Pinto (1906, p.664) destaca que "em 1848, fora, no distrito de Santo Antônio de Juiz de Fora, constituída a Irmandade do Senhor dos Passos [...]". Ao que parece os termos 'distrito', 'localidade', 'arraial', 'povoado' e 'povoação' foram, 
por muito tempo, utilizados indevidamente como sinônimos. Tanto antes da criação legal do distrito, em 1839, quanto depois dessa data se encontram referências tratando Juiz de Fora com uma dessas terminologias. Mesmo após a criação do município, em 1850, a utilização incorreta dos termos continuava. O Jornal O Conciliador, em sua edição de 27 de outubro de 1851, por exemplo, noticiava “[...] a demissão concedida nesta data a Anacleto José de Sampaio do emprego de professor do $1^{\circ}$ grau do arraial do Juiz de Fora" Jornal O Conciliador, 13 de março de 1851, $\mathrm{n}^{\circ}$ 188, p.1).

\section{REPRESENTAÇÃO CARTOGRÁFICA DO DISTRITO DE JUIZ DE FORA}

A partir das informações levantadas, especialmente daquelas dispostas nas leis provinciais 147/1839 e 291/1846 é possível concluir que na década de 1840, a porção sul do vasto município de Barbacena, estava dividida em, pelo menos, quatro distritos: Juiz de Fora, Simão Pereira, São José e São Francisco de Paula, pois só existem, legalmente, demarcações territoriais referentes a essas (e entre essas) unidades. Por essa ótica, o distrito de Juiz de Fora, que abrangeria uma área de $830,593 \mathrm{~km}^{2}$ (dados dessa pesquisa), tinha os seguintes limites: a oeste, com o distrito de São Francisco de Paula; ao sul, com o distrito de Simão Pereira; ao norte, com o próprio município de Barbacena; e a leste, com o município da Pomba, tendo como linha divisória o Rio Cágado.

Uma vez confirmada a condição de Juiz de Fora como distrito de Barbacena passou-se à tarefa, necessária e difícil, de representar cartograficamente seu território. A existência de algumas incertezas não impede a iniciativa de tentar identificar, aproximadamente, pela primeira vez, a fisionomia territorial original do Distrito. Entre as inúmeras dificuldades devem ser destacadas, pelo menos, as seguintes: nas leis que determinavam a abrangência do território distrital era comum o emprego de termos gerais e pouco definidos, como 'pião' ou 'braço da serra', o que 
dificulta sua localização precisa; muitos topônimos empregados à época foram sendo gradualmente substituídos até seu completo desaparecimento, tais como Serra de Domingos Ferreira Marques ou Serrote da Pipa; a utilização de marcos efêmeros, como as fazendas, que desde então passaram por diversas divisões ou desmembramentos, tornando difícil sua reconstituição. Aliás, essa situação só será alterada no século XX, quando o Decreto-Lei $n^{\circ} 311$, de 2 de março de 1938, que "dispõe sobre a divisão territorial do país" estabeleceu em seu Artigo $8^{\circ}$, que os limites interdistritais ou intermunicipais serão definidos "segundo linhas geodésicas entre pontos bem identificados ou acompanhando acidentes naturais, não se admitindo linhas divisórias sem definição expressa ou caracterizadas apenas pela coincidência com divisas pretéritas ou atuais".

O trabalho de representação cartográfica do distrito de Juiz de Fora, em seu território original, teve como fundamentação, duas bases principais, além dos necessários trabalhos de campo: uma base legal e uma base cartográfica. A delimitação cartográfica tomou como base as cartas planialtimétricas do IBGE, na escala 1:50.000, em razão dessa escala permitir maior detalhamento. Outras fontes importantes foram as Cartas Juiz de Fora e Palmira, produzidas em 1924, pela Commissão Geográphica e Geológica de Minas Gerais, na escala 1:100.000, que contém muitas informações toponímicas próximas daquelas utilizadas em meados do século XIX. Também foram utilizadas as informações constantes na Carta Juiz de Fora, de 1937 (edição de 1949), produzida pelo Serviço Geográfico do Exército, na escala 1:50.000. Destaca-se ainda o mapa elaborado pelo tenente João José da Silva Theodoro, que fora encarregado, em 1845, de examinar as divisas entre Minas Gerais e Rio de Janeiro, bem como de elaborar uma planta dos Termos de São João Nepomuceno, São João Batista do Presídio (atual Visconde do Rio Branco) e Pomba. Além do relatório (THEODORO, 1847) produziu um importante e detalhado mapa que abrange boa parte do sul da Zona da Mata, e que atendeu parcialmente aos propósitos dessa pesquisa, por tratar-se de uma obra que abarca um período histórico concomitante ao das leis que criaram o distrito de Juiz de Fora. 
A base legal merece uma explicação importante. Os limites do distrito de Juiz de Fora foram estabelecidos pelas leis provinciais $n^{0}$ 147/1839 e 291/1846, contudo, o disposto nessas duas leis abrange apenas a delimitação sul e oeste do novo distrito, território confrontante, respectivamente, com os distritos de Simão Pereira e São Francisco de Paula. Para o limite leste foi adotado o disposto no Artigo $6^{\circ}$ da Lei 147/1839, que estabeleceu as divisas entre Barbacena (município ao qual Juiz de Fora passava a figurar na condição de distrito) e da Pomba, seguindo-se, basicamente, o traçado do Rio Cágado, que ainda hoje serve como limitação parcial do município. Para o limite norte do distrito, divisa com Barbacena (e, em parte, provavelmente, com a Freguesia do Engenho do Mato), a situação se mostrou mais complexa. Devido à inexistência de legislação específica foi adotado o limite estabelecido pela Resolução de 4 de junho de 1852, que definiu os limites do Distrito e da Paróquia de Santo Antônio do Parahybuna, já na condição de município emancipado. Embora não se constitua em solução ideal, torna-se a mais plausível, tendo em vista ser essa a primeira lei a descrever a limitação municipal naquela região.

Torna-se ainda oportuno enfatizar que a delimitação territorial do Distrito de Juiz de Fora foi disposta apenas por duas leis, de 1839 e 1846, e mesmo nesse intervalo de apenas sete anos, ocorreram inúmeras modificações de dominialidade territorial na região. O desenvolvimento da cultura cafeeira acirrou e intensificou as questões ligadas aos diversos interesses econômicos e políticos. Várias localidades se emanciparam no período, levando a diferentes composições territoriais, além da sistemática alteração de limites entre paróquias e municípios, em razão das constantes transferências de fazendas entre eles. Tudo isso, deve-se registrar, contribui para a existência de algumas incertezas quanto à delimitação das porções norte e leste.

Definidas as bases legais e cartográficas passou-se à demarcação do território do primitivo distrito. Foi construído um mapa base a partir da junção das cartas planialtimétricas do IBGE, na escala 1:50.000 (Folhas Matias Barbosa, Juiz de Fora, Ewbank da Câmara, Mar de Espanha, São João Nepomuceno e Santa Bárbara do 
Figura 1 - Mapa do provável território abrangido pelo Distrito de Juiz de Fora

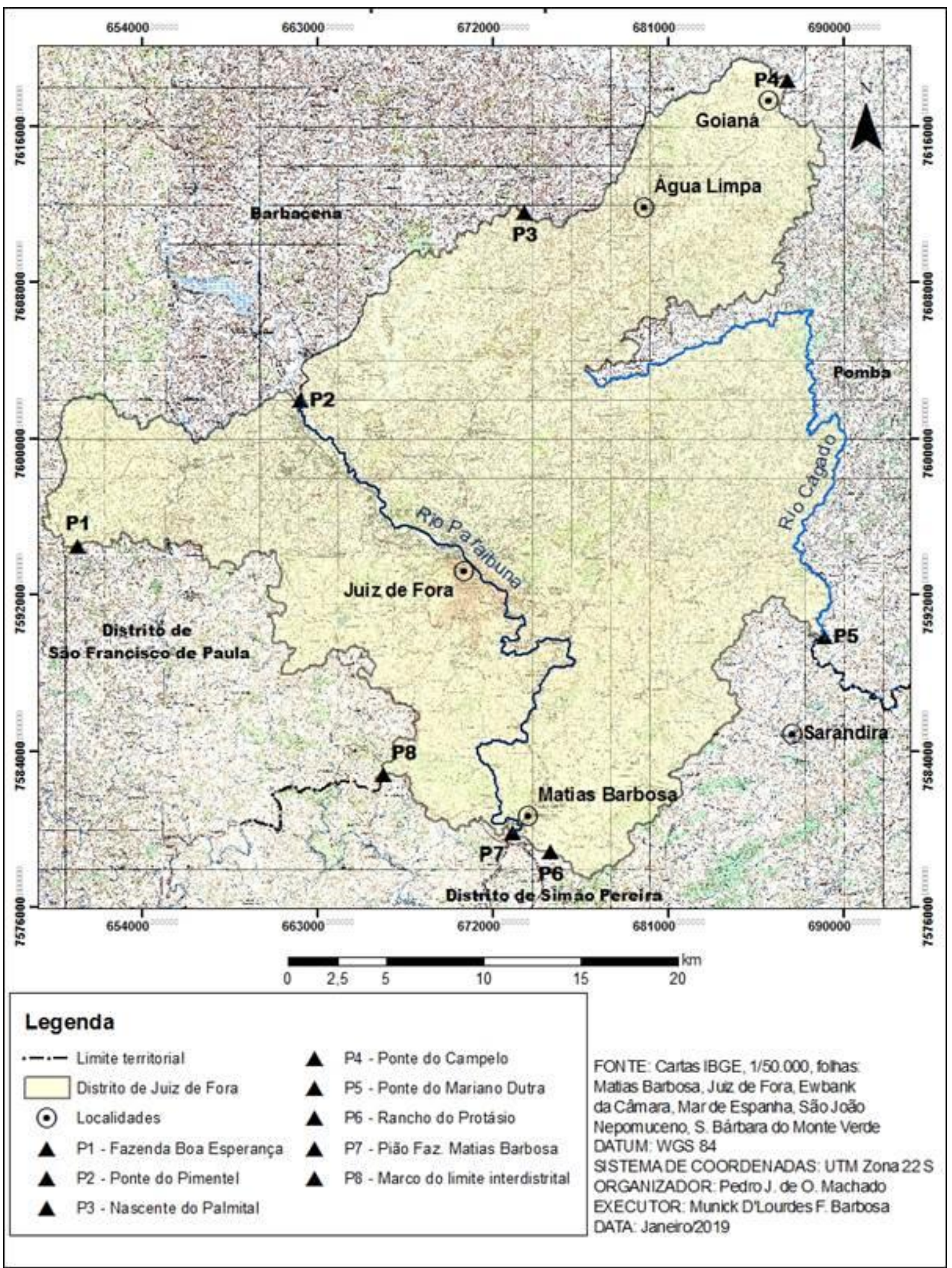


Monte Verde); nesse mapa base foram incluídos, ponto a ponto, todos os limites territoriais, acompanhando a descrição oficial constante nas respectivas leis (como apresentado mais adiante), tudo seguido de constantes incursões a campo; após a finalização do mapa base passou-se aos procedimentos de edição no ArcGis 10.2.2: inicialmente, foi criado um shapefile de polígonos no ArcCatalog, utilizando-se o sistema de coordenadas UTM Zone 22S; depois, utilizando-se da ferramenta Editor do ArcGis, procedeu-se à transposição e digitalização manual dos pontos, resultando no mapa apresentado na figura 1. No mapa foram ainda destacadas algumas referências regionais importantes, de modo a facilitar a identificação territorial, como rios, localidades e 8 pontos de amarração dos limites descritos em lei.

\subsection{Limite Norte (com o município de Barbacena) - Referência legal: Artigo $1^{\circ}$ da Resolução de 4 de junho de 1852}

Artigo $1^{\circ}$ - A divisa do Districto e Paróchia de Santo Antônio do Parahybuna começará na Fazenda da Boa Esperança, que foi do finado Francisco Antônio Correia, e seguirá pelo Ribeirão da Cachoeira até sua barra no do Espírito Santo, por este até o Rio Parahybuna, acima da Ponte do Pimentel pelo Rio Parahybuna até a encruzilhada do caminho d’Água-limpa, e por este passando pela Fazenda d'Antônio Moreira, e Campo Grande até a encruzilhada da estrada do continente, dahi pelas cabeceiras do Ribeirão do Palmital, e por este até o da Água-limpa, e por este até a sua barra no Rio Piau, ou Novo, e por este até a Ponte do Campello [...].

O limite começa na Fazenda da Boa Esperança (P1) (embora fosse essa uma denominação usada por várias fazendas da época, trata-se daquela que pertenceu a Francisco Antônio Correia, localizada junto às nascentes do Córrego Boa Esperança e 
próxima à localidade de Penido); Para atingir o Ribeirão da Cachoeira, a partir dessa fazenda, seguiu-se pelo divisor de águas dos córregos Boa Esperança e Penido, até alcançar a nascente do Ribeirão da Cachoeira, localizada mais ao sul, a cerca de 800 metros de altitude; A partir daí segue-se o curso desse ribeirão até sua foz no Ribeirão Espírito Santo (deve-se observar que na Carta 1/50.000, do IBGE, Folha Ewbank da Câmara, o Ribeirão da Cachoeira aparece com o nome de Córrego Cachoeira, assim prosseguindo até sua confluência com o Córrego Morrinhos, ambos afluentes do Córrego Barreiro, nome que prevalece até a foz no Ribeirão Espírito Santo); Segue-se então o curso do Ribeirão Espírito Santo até sua foz no Rio Paraibuna, num ponto que fica a montante da Ponte do Pimentel (P2), que aparece destacada no Mapa de Theodoro, de 1847, pouco acima do atual bairro Benfica. Cravo (2013) descreve em detalhes o processo construtivo dessa ponte, nos anos de 1839/1840, que fazia parte da Nova Estrada do Paraibuna, aberta por Halfeld, e que distava “duas léguas e meia de Juiz de Fora" (CRAVO, 2013, p.223). A partir desse ponto, o texto da lei não é suficientemente claro, o que implica em se ter várias interpretações e, portanto, várias alternativas de limite. Optou-se por, a partir da confluência entre o Ribeirão Espírito Santo e o Rio Paraibuna, seguir pelo leito desse último até atingir a Ponte do Pimentel e daí até atingir o caminho para Água Limpa (atual Coronel Pacheco), que parece tratar-se da atual Estrada Elias José Mockdeci, que começa no bairro Barreira do Triunfo e margeia o Córrego da Aldeia e depois o Ribeirão dos Burros, até alcançar o entroncamento com a estrada de acesso à Fazenda do Continente (esta estrada, por sua vez, corresponde, em grande parte, ao traçado do novo acesso ao Aeroporto Regional da Zona da Mata, ligando a MG-353, em Coronel Pacheco, ao bairro Náutico, em Juiz de Fora); De acordo com a lei, a partir desse entroncamento segue-se até as cabeceiras do Ribeirão Palmital. Ocorre que entre esses dois pontos existe uma distância considerável, cerca de $6 \mathrm{~km}$. A partir da citada encruzilhada, tomou-se então o primeiro espigão à esquerda, acompanhando o divisor de águas do Ribeirão dos Burros, prosseguindo até atingir uma das nascentes do Ribeirão Palmital, localizada a 780 metros de altitude, entre as fazendas Arrozal e Palmital (P3); Daí segue-se pelo 
traçado desse último curso d'água até sua foz no Ribeirão Água Limpa, e daí, pelo traçado desse último ribeirão até sua foz no Rio Piau ou Novo (nesse último trecho, de acordo com a Carta do IBGE, Folha Juiz de Fora, o Ribeirão Água Limpa, a partir do encontro com o Ribeirão Palmital, figura com o nome de Ribeirão Liberdade); Seguese então pelo curso do Rio Novo até atingir a Ponte do Campelo (P4), próxima à cidade de Goianá (não se trata, certamente, da atual ponte, construída em concreto pelo extinto Departamento Nacional de Obras de Saneamento - DNOS, e inaugurada em maio de 1966, mas da antiga, estreita e de madeira, que de acordo com informações colhidas em campo, ficava ao lado). De acordo com essa interpretação a antiga localidade de Água Limpa ficava inclusa ao território do Distrito de Juiz de Fora. Essa situação é corroborada por Lucas $(1986$, p.6) quando menciona que o primitivo povoado de São Vicente, depois Lima Duarte, Água Limpa e finalmente Coronel Pacheco pertenceu, "desde o início, ao município de Juiz de Fora".

\subsection{Limite Leste (com o município da Pomba) - Referência legal: Artigo $6^{\circ}$ da Lei}

\section{$147 / 1839$}

Artigo $6^{\circ}$ - Os limites meridionais entre os Municípios de Barbacena e da Pomba, serão desde a barra do Rio Kágado, no Parahybuna, seguindo pelo veio daquele acima até as suas cabeceiras, defronte da Serra de Domingos Ferreira Marques, e por esta seguindo as águas, que se encaminham diretamente da Serra da Babilônia à Fazenda de Antônio José Gonçalves, e desta Serra a fechar no Rio Novo, chamado também Piau; ficando para o Município de Barbacena as Fazendas do Capitão Maximiano José Pereira, João de Souza Pereira e do Alferes Ignácio da Silva Campello, sitas na margem do dito Rio Piau.

As leis que definiram a criação e delimitação do Distrito de Juiz de Fora não estabeleceram como já foi mencionado, seu limite leste. Essa questão, contudo, pode ser solucionada, uma vez que a mesma lei 147/1839, que estabeleceu a limitação entre os distritos de Juiz de Fora e Simão Pereira também determinou os limites meridionais entre os municípios de Barbacena e Pomba. Como o Distrito de Juiz de 
Fora estava sendo criado a partir do território de Barbacena parece lógico que sua limitação leste devesse concordar com o limite estabelecido para esse município, ou seja, seguindo basicamente o curso do Rio Cágado. A questão maior, merecedora de especificação, se refere à determinação do ponto, no Rio Cágado, que demarcaria o limite do distrito. Para isso, adotou-se como ponto inicial, a Ponte da Fazenda de Marianno Dutra, referência que consta na Resolução de 4 de junho de 1852, que estabeleceu a delimitação do Distrito e da Paróquia de Santo Antônio do Parahybuna, após sua emancipação. Portanto, a limitação leste do Distrito de Juiz de Fora começa no Rio Cágado, no ponto onde esse era cortado pela Ponte do Marianno Dutra (P5), que parece se localizar na entrada da atual Fazenda da Providência, propriedade originada da partilha das terras pertencentes a Marianno Dutra (VANNI, 1997); A partir dessa ponte o limite segue o curso do Rio Cágado, em direção a montante, até chegar "as suas cabeceiras defronte da Serra de Domingos Ferreira Marques", como determina o Artigo $6^{\circ}$ da Lei 147/1839. A citada serra está destacada no Mapa de Theodoro, de 1847, formando um alinhamento com a Serra da Babilônia. Contudo, esse topônimo não aparece mais em registros cartográficos atuais, podendo-se deduzir tratar-se da denominada Serra da Pedra Bonita, como aparece grafada na Carta do IBGE, escala 1:50.000 (Folha São João Nepomuceno) e que serve de limitação atual entre os municípios de São João Nepomuceno, Rochedo de Minas e Bicas; O limite acompanha o curso do Rio Cágado até sua nascente, localizada a cerca de 870 metros de altitude. Daí passa a acompanhar o alinhamento da Serra da Babilônia que nesse trecho é o divisor natural de águas entre os rios Cágado e Novo (tal como aparece no Mapa de Theodoro, de 1847), seguindo esse alinhamento, em direção à citada Fazenda de Antônio José Gonçalves. Não foi possível localizar com precisão essa fazenda, mas o Mapa de Theodoro, de 1847, traz a localização de uma propriedade de Antônio Gonçalves, exatamente nesse trajeto da Serra da Babilônia. Também na Carta Palmira, escala 1:100.000, da Commissão Geográphica e Geológica de Minas Gerais, de 1924, a presença, no mesmo local, de um curso d'água denominado Córrego dos Gonçalves (atual Córrego da Laje) parece esclarecer a 
localização desse trecho do limite. Seguindo o alinhamento da Serra da Babilônia, passando pelo chamado Morro Redondo, o limite prossegue até findar no Rio Novo, o que se dá na Ponte do Campelo (P4), utilizada para delimitar a porção norte do distrito.

Por esse entendimento, grande parte do território atualmente ocupado pela cidade de Goianá estava incluída no Distrito de Juiz de Fora. Essa situação pode, em princípio, gerar controvérsia, visto tratar-se de uma localidade que se tornou distrito (Lei $n^{\circ}$ 556, de 30/08/1911) e se emancipou (Lei $n^{\circ} 12.030$, de 21/12/1995), a partir do município de Rio Novo e não de Juiz de Fora. Contudo, é importante esclarecer que a lei 147/1839, que estabeleceu parte da limitação do Distrito de Juiz de Fora, também determinou os limites entre os municípios de Barbacena e Pomba (que abrangia toda a região hoje ocupada tanto por Rio Novo, quanto Goianá). Em seu Artigo $6^{\circ}$ deixou explícito que ficariam “[...] para o Município de Barbacena as Fazendas do Capitão Maximiano José Pereira, João de Souza Pereira, e do Alferes Ignácio da Silva Campello, sitas na margem do dito Rio Piau". Essas fazendas foram diretamente responsáveis pelo surgimento do futuro município de Goianá. Maximiano José Pereira de Souza, por exemplo, por volta de 1830, era proprietário das terras onde hoje se acha implantada a Fazenda da Fortaleza (atualmente inclusa a Goianá) e que pertencera à família de Mariano Procópio (COLOMBO e BARBOSA, 2007, p. 57). A posse dessa parte do território foi transferida a Rio Novo (e, depois da emancipação, à Goianá) somente após a criação do Distrito de Juiz de Fora. Noutro caso, a Fazenda do Alferes Ignácio da Silva Campello, que pertencia a Barbacena (Lei 147/1839) e que hoje pertence à Goianá, somente foi incorporada a Rio Novo pela Lei Provincial $n^{\circ} 720$, de 16 de maio de 1855, que em seu Artigo 6 ${ }^{\circ}$ § $5^{\circ}$ determinou: “Fica pertencendo à Freguesia do Rio Novo, no Município de Mar de Espanha, a Fazenda de Ignácio da Silva Campello". A limitação territorial se mostrava tão complexa nessa área que a Lei Provincial $n^{\circ} 731$, também de 16 de maio de 1855, em seu Artigo $3^{\circ}, \S 3^{\circ}$, autorizou o Governo a designar as divisas entre as freguesias de Nossa Senhora da Conceição do Rio Novo e Santo Antônio do Paraibuna. 
Em 1923, portanto após a elevação de Goianá à condição de distrito de Rio Novo, a Lei $\mathrm{n}^{\circ}$ 843, de 7 de setembro, em sua Seção Segunda, Artigo 3, inciso XVI, letra b, retificou as divisas entre Rio Novo e Juiz de Fora. A observação cuidadosa do conteúdo dessa lei faz ver que a posse da porção territorial localizada entre o Córrego do Fundão e o Córrego do Limoeiro foi trasladada do distrito de Água Limpa, pertencente a Juiz de Fora, para o município de Rio Novo, abrangendo exatamente o local onde se acha implantada boa parte da atual cidade de Goianá.

Essas situações exemplificam muito bem como eram fluidos os limites territoriais no século XIX, em especial nesse trecho, o que tornam difíceis e complexas as tentativas de demarcação territorial. Trata-se, nessa época, de uma região caracterizada pela expansão da cultura cafeeira, e que envolvia diferentes interesses políticos e econômicos. Isso gerava uma constante fluidez dos limites territoriais entre paróquias e municípios. O exemplo de Piau, também localizado nessa área, é bastante ilustrativo: entre os anos de 1841 e 1870, a localidade sofreu vários traslados, tendo pertencido aos seis municípios que disputavam o domínio territorial da região (Barbacena, Pomba, São João Nepomuceno, Rio Novo, Mar de Espanha e Juiz de Fora).

\subsection{Limite Sul (com o Distrito de Simão Pereira) - Referência legal: Artigo $3^{\circ} \mathrm{da}$ Lei $147 / 1839$}

Os limites entre os Distritos de Simão Pereira, e do Juiz de Fora, ou da Boiada, no Município de Barbacena, serão além dos das antigas Aplicações às Serras, e Montes mais elevados desde a Fazenda de Matias Barbosa até o Rio, e Distrito do Cágado.

Seguindo-se apenas o disposto neste artigo da lei, a determinação desse limite se torna tarefa bastante complexa, especialmente em razão de a legislação ser muito generalista, numa região de relevo muito movimentado. Não especifica, por exemplo, que ponto adotar como referência na Fazenda de Matias Barbosa, qual o ponto onde 
se encerrará no Rio Cágado ou que alinhamento de serras e montes mais elevado irá seguir. Imaginamos que esses pontos duvidosos possam ser mais bem esclarecidos utilizando-se, conjuntamente, parte do Artigo $1^{\circ}$ da Resolução de 4 de junho de 1852, que estabeleceu os limites do Distrito e da Paróquia de Santo Antônio do Parahybuna, no trecho apresentado a seguir.

[...] até a ponte da Fazenda de Marianno Dutra, e dahi pelos espigões da cordilheira que divide as águas vertentes para o Kágado, e Ribeirão Mathias Barbosa, até o Rancho do Protásio na estrada, e seguirá pelos mesmos espigões até o Rio Parahubuna [...].

Desta forma, pode-se considerar a Ponte da Fazenda de Marianno Dutra (P5), no Rio Cágado, como ponto inicial desse limite, assim como foi feito na limitação leste. A partir dessa ponte toma-se o espigão localizado imediatamente à frente, que limita a bacia do Córrego Pouso Alegre, até encontrar o divisor de águas entre o Rio Cágado e o Ribeirão Matias (ou São Fidelis), próximo às nascentes do Córrego Caetés; Passa-se a percorrer por esse divisor, em direção a Matias Barbosa, ficando, por esse entendimento, excluída da área do Distrito de Juiz de Fora a localidade de Sarandira. Essa situação é, em grande medida, corroborada por alguns fatos que envolvem essa localidade, que nem existia à época da lei 147/1839, pois tem suas origens ligadas à Revolução Liberal de 1842 (ESTEVES e LAGE, 1915, p.471). Vanni, (2013, p.123) esclarece que "na metade do século XIX, os sertões onde surgiram os povoados de Sarandira e Pequeri se confundiam com os de Santana do Deserto, ambos integrantes da freguesia eclesiástica e do distrito de Simão Pereira". De fato, a Lei Provincial $\mathrm{n}^{\circ}$ 2.627, de 7 de janeiro de 1880, que elevou Sarandira à freguesia, enuncia que seu território estava sendo desmembrado da Freguesia de São Pedro de Alcântara, atual município de Simão Pereira. Seguindo-se pelo citado divisor de águas atinge-se o Rancho do Protásio (P6). Protásio Antônio da Silva Pinto era figura importante à época, tendo como irmãos, dentre vários, José Antônio da Silva Pinto, o Barão da 
Bertioga (grande cafeicultor da região) e Maria da Silva Resende, a Condessa de Cedofeita, além de ser pai do influente político José Joaquim Monteiro da Silva, o Barão de Santa Helena, que foi vereador e presidente da Câmara Municipal de Juiz de Fora, deputado, vice-presidente da Província de Minas Gerais e senador. Seu rancho aparece destacado no Mapa de Theodoro, de 1847, o que possibilita sua localização com razoável precisão. Ficava próximo ao Córrego Monte Alegre, na fazenda de mesmo nome e que hoje é um bairro de Matias Barbosa. A estrada que passava por ele, citada na Resolução, era o Caminho Novo (ou uma de suas variantes); A partir desse ponto, segue-se a linha do espigão, até atingir o Rio Paraibuna, passando pelo pião da Fazenda de Matias Barbosa (P7), localidade que, por esse entendimento, ficava inclusa ao território do Distrito de Juiz de Fora.

\subsection{Limite Oeste (com o Distrito de São Francisco de Paula) - Referência legal: Artigo $5^{\circ}$ da Lei $291 / 1846$}

As divisas do Distrito do Juiz de Fora com o de São Francisco de Paula, e Simão Pereira, serão pela Serra dos Pintos, águas vertentes para o Rio Paraibuna, até o Serrote da Pipa, e daí a findar no Pião da Fazenda de Mathias Barboza.

O Pião da Fazenda de Matias Barbosa (P7), citado na legislação, se torna marco referencial importante para delimitação sul e oeste do Distrito de Juiz de Fora. Sua localização é precisada por Castro (1998, p.71), que transcreve a demarcação dos limites da antiga Sesmaria de Matias Barbosa, feita em 1782, a pedido do Tenentecoronel Manuel do Valle Amado, então proprietário das terras.

[...] a bem placito de todos se allegeo para lugar do Pião huma varge próxima as casas de vivenda do mesmo sismeiro, e ahi em distância de vinte e cinco braças mais ou menos do portão do dito Registro, e da parte da Cidade do Rio de Janeiro se meteo na terra entre a estrada da mesma cidade, e muro de pumar das 
casas do dito sismeiro, e defronte de uma ponte que tem no Rio Paraibuna, uma pedra grande com quatro pequenas ao pé em que lavrarão quatro cruzes viradas cada uma para os rumos que se havião de seguir, que ficou sendo o Pião, e deste seguirão os louvados [...]. (CASTRO, 1998, p.71).

A partir do citado 'pião', ou seja, marco de pedra a partir do qual se delimitou a sesmaria, e de acordo com a legislação, o limite atravessa o Rio Paraibuna, logo à frente, e segue pela linha de espigão imediata, que vai levar até as cabeceiras do Córrego Macuco (denominação ainda utilizada na Carta do IBGE, escala 1:50.000, Folha Matias Barbosa), quando se tem um ponto limítrofe entre os distritos de Juiz de Fora, Simão Pereira e São Francisco de Paula (P8), como descrito no Artigo $4^{\circ}$ da Lei 291/1846 (que trata de limites interdistritais), e que fica sobre o divisor de águas entre os rios Paraibuna e Peixe; A partir desse ponto a chamada Serra dos Pintos serve de limite, tanto para as águas que vertem para os dois rios, quanto para os distritos de Juiz de Fora e São Francisco de Paula, passando nesse trajeto pelas cabeceiras do Córrego Grota do Pinto, denominação que muito se assemelha àquela utilizada na legislação (Serra dos Pintos). Prosseguindo-se por esse trajeto se chega exatamente à Fazenda Boa Esperança (P1), marco inicial da limitação do Distrito de Juiz de Fora. Esse último trecho da delimitação territorial encontra grande paralelo com aquela apresentada por Azevedo (1978, p.240), quando destaca os limites do distrito de Torreões (antigo São Francisco de Paula).

\section{CONSIDERAÇÕES FINAIS}

O resultado mais importante dessa pesquisa refere-se à comprovação da existência legal do Distrito de Juiz de Fora. Criado em 1839, teve sua delimitação (sul e oeste) determinada nesse mesmo ano, pela Lei $n^{\circ} 147$ e em 1846, pela Lei $n^{\circ} 291$. Esse se constitui, portanto, no seu primeiro formato territorial e na sua primeira forma administrativa legal. 
O processo de formação territorial de Juiz de Fora é, em grande medida, a história de construção e consolidação da territorialidade de toda porção sul da Zona da Mata Mineira, visto que muitos dos atuais municípios, especialmente de sua microrregião, mantiveram intensas relações territoriais. Boa parte deles pertenceu a Juiz de Fora, na condição de distritos, enquanto outros permutaram territórios.

Estudos sobre a organização territorial da Zona da Mata, referentes ao século XIX, se mostram, na mesma medida, tão estimulantes quanto complexos. A falta de legislação específica, as constantes trocas de domínio administrativo e os vários interesses que caracterizavam esse período de expansão da cultura cafeeira, tornam difíceis (e múltiplas) as conclusões sobre os fluidos limites territoriais regionais.

Que esse artigo estimule novos estudos sobre a formação territorial de Juiz de Fora (e da região), sobretudo com maior aprofundamento cartográfico, de modo a refinar as informações aqui apresentadas. A Geografia tem (ainda) muito a contribuir com os estudos que buscam entender o processo de construção territorial regional.

\section{REFERÊNCIAS}

ANDRADE, F. C. D. Caminhos do Rio a Juiz de Fora: do século XVI a c. de 1820. In: CARVAlHO, M. C. W. (Coord.). Caminhos do Rio a Juiz de Fora. São Paulo: M. Carrilho Arquitetos, 2010. p. 52-90.

ASSEMBLEIA LEGISLATIVA DO ESTADO DE MINAS GERAIS (ALMG) - Disponível em: https://www.almg.gov.br/consulte/publicacoes assembleia/obras referencia/arquivos Idenominacoes.html. Acesso em: 04 abr. 2017.

AZEVEDO, H. O. F. Uma freguesia nas montanhas: subsídios para a história da Paróquia de São Francisco de Paula e do Distrito de Torreões - Juiz de Fora/MG. Juiz de Fora: ESDEVA, 1978.

BARBOSA, W. A. Dicionário Histórico-Geográfico de Minas Gerais. Belo Horizonte: SATERB, 1971. 
BARBOSA, Y. A. Pequena Geografia Histórica de Juiz de Fora: o processo urbano do Caminho Novo ao início do século XX. Juiz de Fora: FUNALFA; Curitiba: CRV, 2017.

BASTOS, W. L. Caminho Novo: espinha dorsal de Minas. Juiz de Fora: FUNALFA, 2004. CÂMARA MUNICIPAL DE JUIZ DE FORA - Disponível em http://www.camarajf.mg.gov.br/geral.php?tipo=HISTHINO\&c=4. Acesso em: 12 mar. 2017.

CARRARA, A. A. Para além de Minas e Currais (e de Minas Gerais): ensaio de caracterização da divisão regional mineira; séculos XVIII e XIX. In: CALAES, G. D.; FERREIRA, G. E. (Eds.). A Estrada Real e a transferência da corte portuguesa. Rio de Janeiro: CETEM/MCT/CNPq/CYTED, 2009. p. 51-64.

CASTRO, J. F. M. Aspectos históricos, culturais e geográficos do município de Guaraciaba-MG. Belo Horizonte: Editora PUC Minas, 2008.

CASTRO, J. F. M. Geoprocessamento de mapas de Minas Gerais nos séculos XVIIIXIX. Belo Horizonte: Editora PUC Minas, 2017.

CASTRO, O. A. Apontamentos para a história de Matias Barbosa. Juiz de Fora: Oficina de Impressão, 1998.

COLOMBO, A. V.; BARBOSA, C. H. R. História e patrimônio cultural na Fazenda Fortaleza de Sant'anna. In: SILVA, W. D. (Org.). Aspectos históricos e culturais do município de Goianá. Goianá/MG: Grafipel, 2007. p. 57-68.

COSTA, J. R. Toponímia de Minas Gerais - Com estudo histórico da Divisão Territorial e Administrativa. Belo Horizonte: BDMG Cultural, 1997.

CRAVO, T. A. Pontes e estradas em uma província no interior do Brasil: engenharia, engenheiros e trabalhadores no universo construtivo na infraestrutura viária de Minas Gerais (1835/1889). 2013. 348p. Dissertação (Mestrado em História) Universidade de São Paulo (USP), São Paulo. 
ERTHAL, R. Geografia Histórica: considerações. Revista GEOgraphia, Ano V, n. 9, p. 29-39, 2003.

eSteVES, A; LAGE, O. V. B. Álbum do Município de Juiz de Fora. Belo Horizonte: Imprensa Oficial do Estado de Minas Gerais, 1915.

FAZOLATTO, D. Juiz de Fora: Primeiros tempos. In.: NEVES, J. A. P.; DELGADO, I. J. G.; OLIVEIRA, M. R. (Orgs.). Juiz de Fora: história, texto e imagem. Juiz de Fora: FUNALFA, 2004. p.7-18.

FAZOLATTO, D. Juiz de Fora: imagens do passado. Juiz de Fora: Panorama Editora, 2007.

FERREIRA, T. P. Redes e Território: estudo de caso do Município de Simão Pereira MG. 2017. 184p. Monografia (Bacharelado em Geografia) - Universidade Federal de Juiz de Fora, Juiz de Fora/MG.

GIOVANINI, R. R. Regiões em movimento - um olhar sobre a Geografia Histórica do Sul de Minas e da Zona da Mata Mineira (1808-1897). 2006. 204p. Dissertação (Mestrado em Geografia) - Universidade Federal de Minas Gerais, Belo Horizonte/MG.

GODOY, M. M. et al. Negociantes e tropeiros em um território de contrastes: o setor comercial de Minas Gerais no século XIX. In: V CONGRESSO BRSILEIRO DE HISTÓRIA ECONOMICA E $6^{\circ}$ CONFERÊNCIA INTERNACIONAL DE HISTÓRIA DE EMPRESAS, Belo Horizonte. Anais do V Congresso Brasileiro de História Econômica. Belo Horizonte: ABPHE, 2003. p.1-38.

GUIMARÃES, F. N. Fundação histórica de São João Del-Rei. In: DANGELO, A. G. D. (Org.). Origens históricas de São João Del-Rei. Belo Horizonte: BDMG Cultural, 2006. p.11-63.

INSTITUTO BRASILEIRO DE GEOGRAFIA E ESTATÍSTICA (IBGE). Enciclopédia dos Municípios Brasileiros (Vol. XXV. p.380-405). Rio de Janeiro: IBGE, 1959.

INSTITUTO DE GEOCIÊNCIAS APLICADAS (IGA). As denominações urbanas de Minas Gerais: cidades e vilas mineiras com estudo toponímico e da categoria administrativa. 
Belo Horizonte: Instituto de Geociências Aplicadas/Assembleia Legislativa de Minas Gerais, 1993.

LESSA, J. Juiz de Fora e seus pioneiros (do Caminho Novo à Proclamação). Juiz de Fora: UFJF, 1985.

LUCAS, A. P. Reminiscências de Coronel Pacheco. Juiz de Fora: ESDEVA, 1986.

MACHADO, P. J. O.; SANTOS, F. A. S. Evolução político-administrativa do Município de Juiz de Fora/MG. In: V SEMINARIO DE PÓS-GRADUAÇÃO EM GEOGRAFIA DA UFJF, Juiz de Fora/MG. Anais do V Seminário de Pós-graduação em Geografia/UFJF. Juiz de Fora: UFJF, 2017. p. 73-87.

MACHADO, P. J. O. Evolução demográfica do Município de Juiz de Fora/MG, no período 1850/1920: população, café e território. In: GOMES, I. A. (Org.). A Geografia na Contemporaneidade 2. Ponta Grossa/PR: Atena Editora, 2018a. p. 294-308.

MACHADO, P. J. O. Saúde e Saneamento nas Posturas Legais de Juiz de Fora/MG do século XIX. Revista Hygeia, v. 14, n. 29, p.25-36, 2018 b.

MATOS, R. J. C. Corografia histórica da Província de Minas Gerais (1837). Belo Horizonte: Itatiaia; São Paulo: Editora USP, 1981.

MINAS GERAIS (Tribunal de Justiça do Estado de Minas Gerais). Comarcas de Minas. Belo Horizonte: Imprensa Oficial de Minas Gerais, 2016.

MOURA, A. B. A. P.; MACHADO, P. J. O.; ZAIDAN, R. T. Ordenamento territorial de Juiz de Fora/MG: uma análise das divisões territoriais urbanas. Revista de Geografia, v. 7, n.1, p. 91-106, 2017.

O CONCILIADOR - Jornal, 13 de março de 1851, n 188, p.1 - Disponível em: http://memoria.bn.br/DocReader/docreader.aspx?bib=847364\&pasta=ano\%20185\&p esq=Juiz\%20de\%20Fora. Acesso em: 26 abr. 2018. 
O UNIVERSAL - Jornal, em 19 de maio de 1830, n 442, p.2. - Disponível em: http://www.siaapm.cultura.mg.gov.br/modules/jornaisdocs/photo.php?lid=104883.

Acesso em: 16 out. 2017.

OLIVEIRA, P. Dois povoados distintos constituíram a cidade de Juiz de Fora. Revista do Instituto Histórico e Geográfico de Minas Gerais. v. V, p. 55-63, 1958.

OLIVEIRA, P. História de Juiz de Fora. Juiz de Fora: UFJF, 1966.

PINTO, A. Apontamentos históricos do município de Juiz de Fora. Revista do Arquivo Público Mineiro. v. 11, n. 1, p.641-667, 1906.

PREFEITURA MUNICIPAL DE BARBACENA - Disponível em: http://barbacena.mg.gov.br/2/noticias/?id=4676. Acesso em: 03 mar. 2017.

SANTIAGO, S. B. Juiz de Fora à luz da história e dos documentos. Revista do Instituto Histórico e Geográfico de Juiz de Fora. Ano VIII, n. 8, p.17-36, 1979.

SANTIAGO, S. B. Primeiro documento oficial dando a este lugar o nome de Juiz de Fora. Revista do Instituto Histórico e Geográfico de Juiz de Fora. Ano IX, n. 9, p.2324, 1985.

SARAIVA, L. F.; SILVA, L. F. Minas Gerais, Regionalização e Identidade 1821-1893. In: XIV SEMINARIO SOBRE ECONOMIA MINEIRA. Diamantina/MG. Anais do XIV Seminário sobre economia mineira. Belo Horizonte: UFMG, 2010. P.01-25.

THEODORO, J. J. S. Relatório do Tenente João José da Silva Theodoro, encarregado pelo Exmo. Sr. Doutor Quintiliano José da Silva, Presidente da Província de Minas Gerais, de levantar o mapa topográfico dos municípios do Presídio, Pomba e São João Nepomuceno e de verificar as divisas entre a dita província, e as do Rio de Janeiro e Espírito Santo pelo lado de Campos e Itapemirim. Ouro Preto: Tipografia Echo de Minas, 1847.

VALVERDE, O. Estudo regional da Zona da Mata de Minas Gerais. Separata da Revista Brasileira de Geografia, Rio de Janeiro, Ano XX, n.1, p. 3-82, 1958. 
VANNI, J. C. Sertões do Rio Cágado. Jornal o Município. Pequeri/MG, n. 2.361, p.3, edição de 31 de maio de 1997.

VANNI, J. C. Sertões do Rio Cágado: origem de povoados, vilas e cidades que integram a bacia hidrográfica do Rio Cágado. Niterói: Editora Comunitá, 2013.

VEIGA, J. P. X. Ephemérides Mineiras (1664-1897). Ouro Preto: Imprensa Official do Estado de Minas Gerais, 1897. 